\title{
Attrition to completion progression theory in an associate degree nursing program
}

\author{
Carmela Theresa Timbol de Leon* \\ Department of Nursing, Pima Medical Institute, Mesa Campus, United States
}

Received: October 1, 2019

Accepted: January 11, 2020

Online Published: February 17, 2020

DOI: 10.5430/jnep.v10n5p11

URL: https://doi.org/10.5430/jnep.v10n5p11

\begin{abstract}
Objective: This study aimed to develop a substantive theory on the process of overcoming attrition among returning students in an Associate Degree Nursing program in a private school in Arizona.

Methods: A qualitative design was utilized for this study. The Classical Grounded Theory approach provided a systematic process of data collection, analysis and synthesis that led to the emergence of the Attrition to Completion Progression Theory. Theoretical sampling through in-depth interviews of ten participants who experienced temporary attrition and was successfully able to come back to succeed within the program provided a rich source of data and unique perspective of the phenomenon.

Results: Four themes emerged from the grounded theory approach. The themes that emerged are: Attrition as an interplay of multiple factors; Ways of coping with attrition; Changes and modifications; and Finding new meanings as the core category. The emergent theory provided an insight into the process that the participants went through and the perceived contributory factors leading to the attrition.

Conclusions: Understanding the interplay of these factors paved for a better understanding on how current and future students, faculty, and administrators can prevent attrition and assist returning students to become successful in the program towards completion.
\end{abstract}

Key Words: Attrition, Nursing, Grounded theory, Factors, Returning students

\section{INTRODUCTION}

The current nursing shortage universally has brought about multiple issues that need to be addressed in the field of nursing education. As reported in the Bureau of Labor Statistics' (2013) Employment Projections 2012-2022, registered nursing is one of the professions with the highest projected job growth rate over the next decade. It is projected by 2022 that 1.05 million new job openings for nurses will open due to growth and replacement needs. ${ }^{[1]}$ At the moment, the shortage of nurses is driven by an increase in the nation's elderly population, coupled with a sharp increase in the need for chronic care management. ${ }^{[1]}$

The shortage is further compounded by the retirement of experienced nurses and shortage of qualified nursing faculty that limited the ability of nursing schools to expand the capacity to meet rising demands. The average registered nurse (RN) turnover rate in 2014 was $17.2 \%$ (up from $13.5 \%$ in 2011 ) with $24.2 \%$ of hospitals reporting a vacancy rate of $10 \%$ or greater. ${ }^{[1]}$ The rising rate of attrition among undergraduate nursing students, the main focus of this study, plays an integral and essential role in the dire national nursing shortage.

\footnotetext{
* Correspondence: Carmela Theresa Timbol de Leon; Email: cdeleon@pmi.edu; Address: Department of Nursing, Pima Medical Institute, Mesa Campus, United States.
} 
In response to these concerns, multiple efforts have been implemented by health care organizations, legislative bodies and academic institutions. The efforts can be grouped into three strategies. ${ }^{[2]}$ The first strategy is directed toward modifying the existing workplace to retain nurses who are currently working. The second strategy is to change the image of nursing through increased marketing efforts to recruit more students into nursing programs. The third strategy is to alleviate the shortage of nurses by retaining current nursing students to decrease attrition rates and conversely improve program completion rates. This strategy has become vital in light of the nursing and nursing faculty shortage.

On average, U.S. attrition rates have been reported to be $50 \%$ for students enrolled in baccalaureate nursing programs and $47 \%$ for students enrolled in associate degree nursing programs. ${ }^{[3]}$ In comparison, there is apparently no central record of student nurse attrition in the United Kingdom (UK), but in 2006, the Royal College of Nursing claimed that nationally the figure was $25 \% .{ }^{[4]}$ Nursing student attrition undermines the constant supply of nursing workforce that has a strong correlation to achieving and maintaining patient safety. It is more pertinent now to determine the factors contributing to student attrition in order to find solutions to identify and provide early interventions for these students. A number of studies have been done focusing on the predictors of attrition or on the attributes of nursing students at-risk for attrition, but very limited on the actual process of how attrition occurred.

In a private nursing school in Arizona that offers an Associate Degree program, where the researcher is a faculty member, the institutional attrition rate for nursing averages about six to eight percent per cohort. This is relatively modest compared to the $47 \%$ attrition for students enrolled in associate degree nursing programs in the United States. ${ }^{[3]}$ The said institution also has no official existing workflow procedure on how to deal with at risk students who have experienced temporary attrition other than dealing with each student on a case-to case basis. The purpose of this study is to develop a substantive theory to describe the process of attrition and the transition of the returning students to completion of the program.

\subsection{Philosophical underpinnings}

A qualitative grounded theory approach was selected. The philosophical underpinnings of Classic Grounded Theory approach that was originated by Glaser and Strauss ${ }^{[5]}$ will allow the researcher to discover the process of overcoming attrition among returning nursing students in an Associate Degree Nursing program in a private nursing school in Arizona.

This inductive approach by Glasser and Strauss, which fol12 lows a set of procedures to systematically generate theory from data coming from returning nursing students after a period of temporary attrition, will assist in exploring the process that these returning students went through. The Classical Grounded Theory approach is a process of discovery that begins with theoretical sampling and the constant comparative analysis of data as they are gathered.

The process starts with the researcher identifying the problem and specific research questions followed by the cyclical and simultaneous process of data gathering and analysis typical of Classical Grounded Theory approach. In grounded theory studies, theoretical sampling occurs as the data collection progresses.

After each interview and transcription, the data will go through different levels of coding (e.g. open coding, axial coding, and selective coding) until core categories are identified through the constant comparison method ending with the development of a substantive theory based on the core concepts emerging and grounded on the data collected. The comprehension of grounded theory method is partly dependent on an awareness of the method's ontological, epistemological, and methodological perspectives. This study utilized a constructivist approach but followed the steps of Classical Grounded Theory method.

Constructivism aims at an interpretive understanding of participants' meanings. ${ }^{[6]}$ Data are composed through an ongoing interaction between researcher and the participants. The researcher's interpretative comprehension of how participants create their understanding and meaning of reality is the result of the analysis. ${ }^{[6]}$

Other theoretical perspectives or underpinnings are considered once core categories from the data have emerged. This is what is unique in Classical Grounded Theory, where literature in the area under study is reviewed last, when the core category has emerged. The core category is the concept that explains how participants resolve or solve their main concern and is related to all the other concepts in explaining behavior. $^{[7]}$

\subsection{Statement of the problem}

This study aimed to develop a substantive theory on the process of overcoming attrition among returning students in an Associate Degree Nursing program in a private nursing school in Arizona through a grounded theory approach.

This study specifically answered the following questions:

1) What are the perceived factors that contributed to the period of temporary voluntary or involuntary attrition during the Associate Degree Nursing program? 
2) What is the process the returning students have gone through towards successful completion of the program?

3) What substantial theory can be proposed to explain the process experienced by the participants from attrition to completion of the Associate Nursing Degree Program in Arizona? 4) What additional student resources or support system would assist in decreasing student attrition rate in the Associate Degree Nursing program?

5) What are the implications of the developed theory to the institution?

\section{METHOD}

\subsection{Research design}

A qualitative design was utilized for this study. According to Gillis and Jackson ${ }^{[8]}$ a qualitative design must include participants with firsthand knowledge of the phenomenon under study. Classical Grounded Theory method was used specifically to develop a substantive theory or model on the process of overcoming attrition among returning students in an Associate Degree Nursing program in a private nursing school in Arizona. Utilizing a qualitative research approach for this study provided the opportunity to generate rich data related to the experiences of returning students who had undergone temporary attrition during their stay in an Associate Degree Nursing program. The decision to temporarily leave the program was a result of single or multiple factors.

\subsection{Participants of the study}

The participants were students from the school years of 2015 to 2018. They consisted of returning students from an Associate Degree Nursing Program in a private nursing school in Arizona, regardless of gender, that have experienced voluntarily or involuntarily reasons for temporary attrition from the Nursing program. The participants are also current residents within the state of Arizona during the time of this study that helped facilitated the face-to-face interviews.

Sample size in this grounded theory method was theoretical. Theoretical sampling was utilized in this grounded theory study since the sample size was determined through simultaneous and continuous data collection; data analysis and theory construction as the study progressed; and theoretical saturation was reached among the emerging categories and or themes. Theoretical saturation pertains to collecting data until no new incidences or variations in behavior (properties) of a concept emerge. ${ }^{[5]}$ Participants were returning students who met the inclusion criteria. This data was obtained from the change of status (COS) form that these students filledup and was submitted to the school registrar as well as to the Free Application for Financial Student Aid (FAFSA) program that was tracked in each cohort.

\subsection{Research instruments}

This study utilized a semi-structured interview guide with open-ended questions to conduct face-to-face recorded interviews with the study participants that are residing within the state of Arizona. The initial interview guide was subjected to a content validity review by three experts in qualitative research to minimize ambiguity in the question structures prior to use with the first two piloted participants. Yow ${ }^{[9]}$ suggested the use of interview guides to assist the interviewer in pursuing specific topics but not hinder the participants' ability to discuss other pertinent issues. The interview guide was not a questionnaire but a plan that was flexible to allow further exploration of vague topics or answers between the researcher and participants during the face to face interviews. Memos written during the face-to-face interview as well as memos on the margins of interview transcription were utilized during data analysis of the richly textured data resulting from the ten participants.

The researcher also utilized an electronic voice recorder, journal notebooks, pens, colored markers, computer desktop and printer in the process of recording, transcribing and printing of all research materials.

\subsection{Data collection procedure}

To ensure an ethical foundation of this study, the researcher submitted a detailed proposal of the study to the respective ethical review committees of St. Paul University Philippines and to the Institution of the Associate Degree Program in Arizona following institution policies. Upon receiving approval from both institutions, the researcher proceeded with the recruitment of study participants with the assistance of the institution's Registrar's Office. A stringent review of the change of status (COS) forms and FAFSA forms at the campus registrar's office as well as each cohort's end of semester reports from the school years 2015 to 2018 was done to determine study participants that meet the inclusion criteria for this study. After each prospective participant agreed to participate, the researcher set-up a time for a face-to-face audio-recorded interview on a time that was convenient to the participant. Face to face audio-recorded interviews were conducted. As each interview was concluded, verbatim transcription was completed by the researcher, allowing repetitive immersion and exposure with the raw data from each participant. The transcription of each narrative was checked for errors by listening again to the taped interview. A copy of each individual transcription was sent to each participant to first verify content as well as to correct any possible ambiguity or errors. As the different levels of coding and themes started to arise, the researcher contacted each participant and provided a copy of the emerging substantive theory to 
confirm each participant's thoughts or concerns.

\subsection{Data analysis}

Data collection and data analysis are done concurrently during this Classical Grounded Theory study. It is imperative in grounded theory that the researcher becomes immersed in the data from the onset of data collection. Constant comparison method involves comparing elements existent in one data source (e.g. an interview) with another. Constant comparison is the process of comparing every piece of data to every other piece. Data are then coded with previously generated concepts in mind. This involves comparing incident to incident and discovering what happened, how it happened and what caused it to happen from the perspective of participants. ${ }^{[5]}$ Similar incidents are coded in the same way so that researchers are not overwhelmed by generating too many concepts. Simultaneous coding, categorizing and analyzing were performed after each interview and transcription.

This study utilized a color-coding system to highlight significant participant's statements. Drawing out of every expression directly associated with perceived factors of attrition was done as well as the perceived factors that helped overcome temporary attrition. Through open coding, information was broken down into incidents where similarities and differences were explored.

Open coding originated from significant statements directly extracted from the language of the participants. Then, the researcher continuously compared new codes (constant comparison method) with previous ones and consolidated portions of data with similar meanings. These data collection decisions were carefully noted on the margins of the transcription data as well as in a separate journal for ease of tracking and cross-referencing as the common themes emerged.

Axial coding is the next phase of data analysis. It is used to reconstruct or put the data back together in new ways by making connections between the emerging categories. During this phase of the study the researcher looked for causal and or contextual conditions that may have influenced the study participants' actions and decisions during the time of temporary attrition. This phase assisted the researcher in the next level of the coding process.

Selective coding followed, which involved re-examination of the developed categories and the connections between them. Selective coding also describes the relationships between the categories and concepts in a way that explains to others what was going on in the data. This phase provided a clear, logical and comprehensive analytical story, a model or a theory of the process under investigation.

Finally, theory development is the last step in data collec- tion and analysis in grounded theory method of research that describes what has been seen in the data as clearly and succinctly as possible. ${ }^{[5]}$

\section{RESULTS AND DISCUSSIONS}

Five hundred fifty-nine significant phrases were initially coded and analyzed using the constant comparison method. The narratives were also broken into the emerging time-line of the attrition experience as related by the participants into four distinct phases: Pre-attrition, Attrition, Transition and Post-attrition. This helped facilitate the analysis of the emerging themes for each phase.

Further analysis of the open codes resulted into a total of 11 axial themes that emerged as the overreaching themes for each phase the participants experienced. In the Pre-attrition Phase three axial themes of: status quo of coping strategies, awareness of possible attrition, and ineffective coping strategies emerged. The Attrition Phase generated three axial themes of: initial reactions, keeping busy and realizations. The Transition Phase resulted into two axial themes of: reintegration dynamics and exploration of changes. The Post-attrition Phase had three axial themes of: maintaining changes, regression and finding new meanings.

The axial themes for each phase was further analyzed and compared. This resulted in three selective themes and one core category used to build the substantive theory to illustrate the Attrition to Completion Progression Theory that emerged from this study. The three selective themes and one core category are the summative themes for each phase of the experience: attrition is interplay of multiple factors, ways of coping with attrition, period of changes and modification, and the core category of finding new meanings.

\subsection{What are the perceived factors that contributed to the period of temporary voluntary or involuntary at- trition during the Associate Degree in Nursing pro- gram?}

A total of 129 significant entries were coded related to the topic of perceived factors that contributed to each participant's attrition episode. It is significant to note that each of the participants all attributed their attrition experience to more than one factor. This finding coincides with the results of attrition studies that view attrition as a complex phenomenon where students rarely leave for a single reason. ${ }^{[4,10,11]}$

Further content and thematic analysis of the initial 129 entries resulted into four axial themes. The four axial themes are: personal issues, work-related demand, family-role conflict and school associated issues. Seven of the ten participants 
indicated a factor from each of the resulting category, except the four axial themes resulting from the interviews. for four of the participants who did not work during their stay in the program. See Figure 1 that summarizes and illustrates

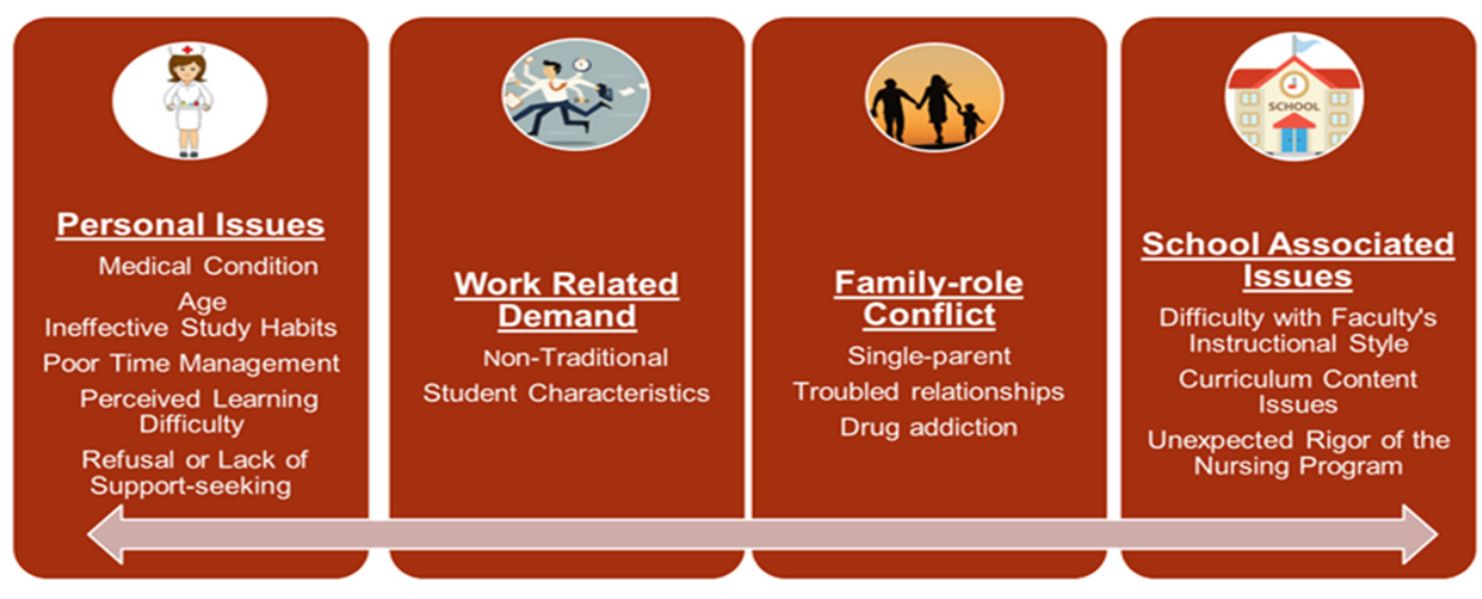

Figure 1. Perceived Factors that contributed to the period of temporary

3.2 What are the phases of the process that the returning students have gone through towards successful completion of the program

After the open and axial coding of the participants' attrition experiences, it was noted that situating their memories were better facilitated when relayed in the chronology by which they happened. This resulted in the four phases of their attrition to completion journey through the nursing program.

The emerged process is divided into the four distinct phases of: Pre-Attrition Phase, Attrition Phase, Transition Phase and Post-attrition Phase. Based on the participants stories, the Pre-Attrition phase starts from the beginning of the 16week semester up to end of the semester where the student after failing a course had to sign the change of status form from active to inactive student status until the failed course is available for re-take.

\subsubsection{Pre-Attrition phase}

A total of 106 significant entries were coded under this phase. The Pre-attrition Phase yielded three axial themes from the participants' thick description of their experiences. The three themes, in the chronology by which the patterns emerged, are: status quo of coping strategies, awareness of the possibility of attrition and ineffective coping strategies.

\subsubsection{Attrition phase}

The Attrition Phase started from the time the student went into inactive status and had to wait out four months to retake the failed course. A total of 106 significant phrases where coded during open coding for this phase. Constant comparison and analysis of the participants' thick description of experiences resulted in three axial themes. The three themes Published by Sciedu Press are: initial reactions, keeping busy and realizations.

\subsubsection{Transition phase}

This phase begins from the time the participant had to go back to school to retake the failed course by joining a new cohort of students up to the end of that 16-week semester when they pass the course. There were 123 significant statements that stemmed from the Transition Phase during the open coding process. After constant comparison and analysis of the thick descriptions of the participants' experiences, two axial themes ensued: reintegration dynamics and exploration with changes.

\subsubsection{Post-attrition phase}

This phase pertained to the time the participant came back as a full-time student after taking only one course in the transition phase or auditing the other courses. This phase includes all the remaining semesters the participant completed from the period of attrition. There were 95 significant phrases coded during the open coding process. The Post-attrition Phase ended with three axial themes of: maintaining the changes, regression and finding new meanings.

Figure 2 is used to illustrate the process that the returning students have gone through. It is divided into four distinct phases that will be discussed subsequently in this chapter. It is significant to note that a curving line was used to represent the ups and downs of the participants' emotions as they experienced each phase of the process of attrition to completion in the program. The bold horizontal line traversing across each phase represents the participants' baseline state of emotions when they started the program during the pre-attrition phase. The participants' emotions and sense of well-being 
started trending downwards as they struggled through the rigors of the program and the multiple perceived factors of attrition that each participant has identified in each of their unique life circumstances. The curving line reached its lowest point during the attrition phase when each participant was officially informed of the involuntary academic attrition and had to sit-out a semester while waiting to retake the failed course. The lowest point in the curve represents the sense of failure that each participant has expressed as the initial feelings they experienced during this point of their academic journey. The curve starts its slow ascent as each participant reached their individual realizations and personal meanings of the attrition phase and started to prepare themselves to transition back into the program. The curve continues its upward trend as each participant explored and made changes to their respective perceived contributory factors of attrition. Subsequently, it can be noted that as each participant surpassed the transition phase of the process by achieving a passing grade for the failed course, the curving line starts to ascend higher as well. The participants' emotions continue to rise, as represented by the upward curve and progressing into the ensuing semesters of the program and eventual successful completion of the program. The curve ends up at a higher point than the initial baseline level compared to when they started the program. This upward trend represents the positive new meanings that all the participants have realized in hindsight after completing the program.

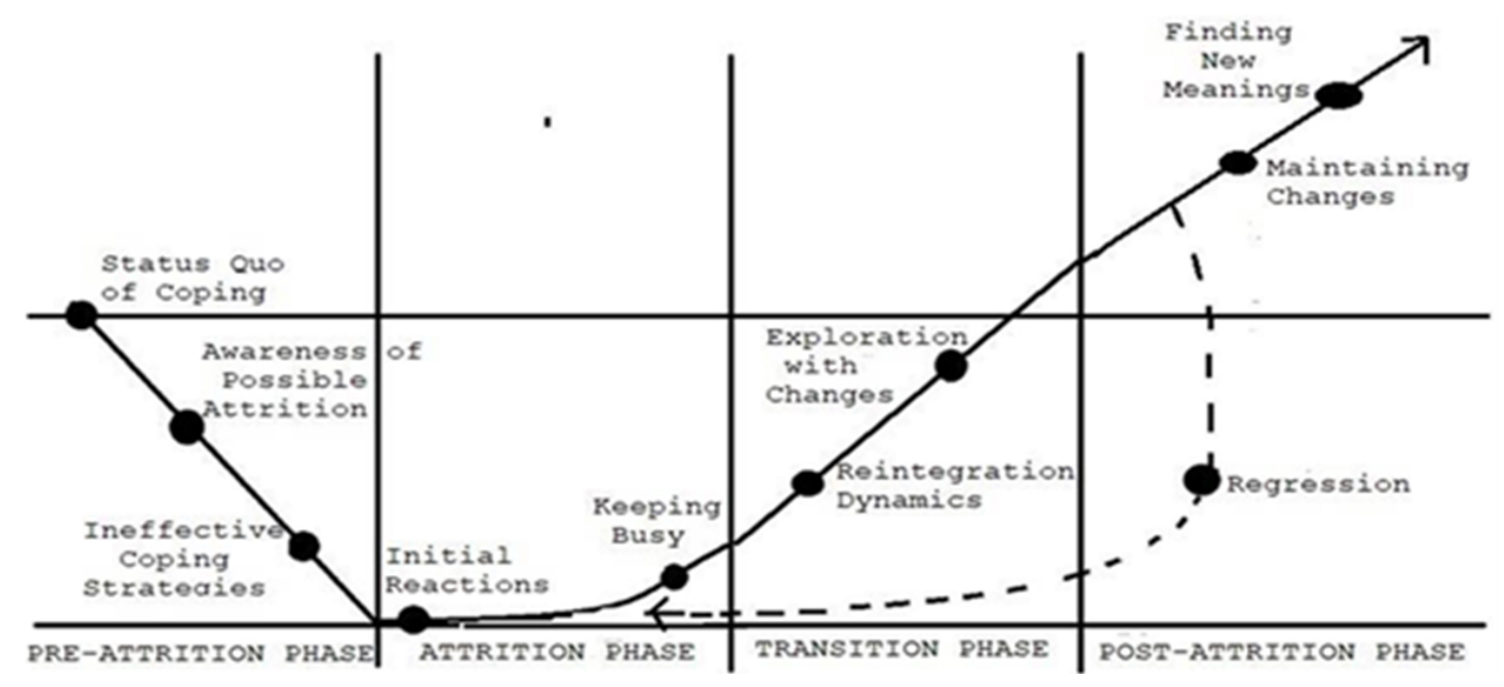

Figure 2. Phases of the process of attrition to completion

Between the themes of maintaining the changes started in the transition phase of the process and the final theme of finding new meanings is the outlying regression point for two out of the ten participants that experienced a repeat attrition due to another failed course after the initial successful transition phase. This part of the process was represented by a broken line curving back downwards to the attrition phase. This experience, as described by the two participants who faced a second episode of attrition expressed another period of feelings of failure and regret at sliding back to another period of attrition. During this regression to the repeat attrition phase, the two participants had to again reflect and realize the perceived causes of this second attrition compared to the first one. The two participants who experienced this attrition again rallied through the experience by modifying their existing coping mechanisms and building new ones in order to succeed to the remaining phases of transition and post attrition phase until they have finally completed the program.

\subsection{Attrition to completion progression theory}

The resulting Attrition to Completion Progression Theory illustrates (see Figure 3) the three main themes and one overreaching core category that emerged after further constant comparison and analysis of each phase of the attrition process. The three main themes include: Attrition is an interplay of multiple factors, Ways of coping with attrition, then lastly Changes and modifications. The core category is Finding new meanings.

\subsubsection{Attrition is an interplay of multiple factors}

The different contributory factors perceived by the participants were clustered under: personal issues, work related demands, family-role conflict and school associated issues. In Figure 3, it can be noted that these four category clusters of personal issues, work related demands, family-role conflict, and school related issues are interconnected to each other. These four cluster categories are also interconnected to the two other main themes. This is important to note since 
each participants' inherent co-existing contributory factors were present from the pre-attrition all the way to the time the participants overcame the attrition and became successful in the program. The only difference from before and after the attrition experience is the degree of burden or support each cluster contributed to each participants' outcome. Each of the four cluster categories are also relevant during the time of attrition, transition and post-attrition as the participant tried to find the perfect balance between the demands of each of the clusters. Finding the effective balance was possible once each participant arrived at a realization of what each phase meant for them and the new meaning, they attached to it that motivated them to change the status quo of their perceived contributory factors to attrition. That is the reason why each of the three main themes was all connected to the core category of Finding New Meanings. As each participant progressed to the next phase of their journey into the program, various realizations on each phase propelled each one into prioritizing the best decision available during that period in their lives. This coincides with two of the story lines from the narrative inquiry of the stories of nursing student repeaters done by Lewis, ${ }^{[12]}$ that outline their experi- ence as: "Nursing school happens in the midst of Life"; ${ }^{[12]}$ and "Nothing can really prepare you for nursing school. ${ }^{[12]}$ These story lines are similar to how the ten participants of this study realized that in spite of all their struggles before, during and after the period of temporary attrition, the world continues to revolve around them. As well as the realization that in spite of the best plans, things happen (e.g. death in the family and issues with drug addiction in the family) and they had to continuously cope and modify their pre-existing coping mechanisms to stay on top of these challenges. The ten participants related how their unique personal experiences led to failing a course and going into involuntary attrition. The theme of Attrition is an interplay of multiple factors is in line with the study done by Tabi et al. ${ }^{[13]}$ that gave an example how excessive workload and inadequate time related to family responsibilities are associated with attrition in the nursing student population. Another study in line with this theme was done by Yucha, et al. ${ }^{[14]}$ which stated that today's college students experience greater stress than students in the past, given that many have work and have family responsibilities in addition to their academic course work.

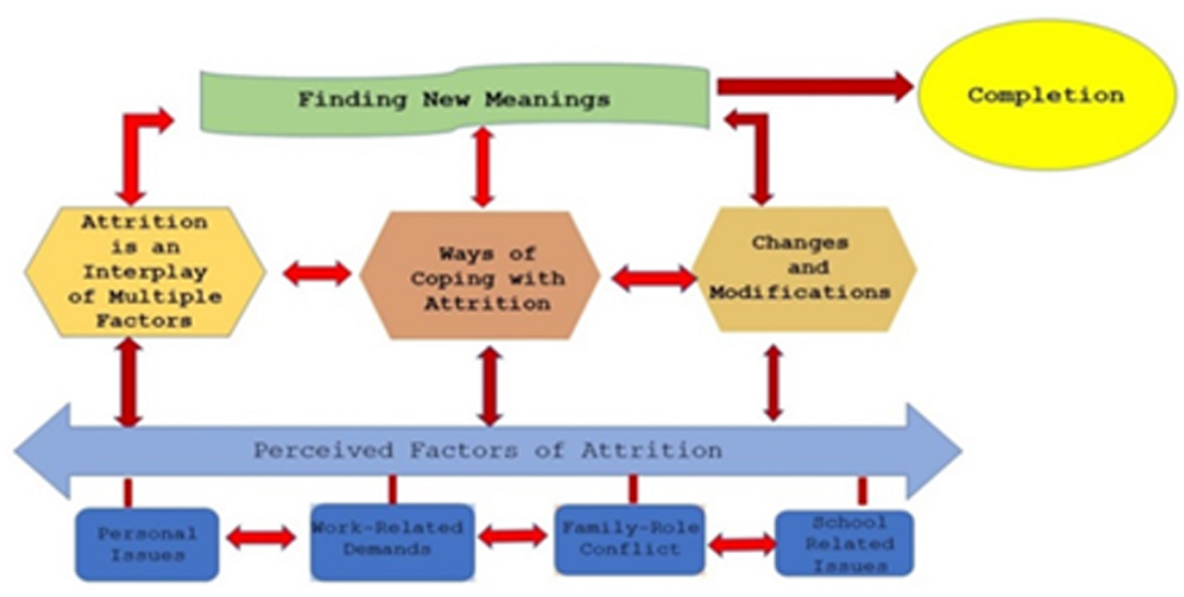

Figure 3. Attrition to completion progression theory

\subsubsection{Ways of coping with attrition}

This theme includes the tumult of emotions that the participants experienced through the different phases of attrition. This theme is in line with a narrative inquiry study by Lewis ${ }^{[12]}$ that analyzed the unique experiences of 14 participants who had failed a nursing course and had to repeat it. One of the main story lines identified in this study was how these participants saw "Repeating as an emotional journey". ${ }^{[12]}$ This story line coincides with the emotional roller coaster that the participants worked through from the Preattrition phase and mostly during the four months that they were in the Attrition Phase. An important aspect of this theme is when the participants each took the time to reflect on the factors that they were juggling in the pre-attrition phase and acknowledging their role in the failure of the course. This crucial part of acknowledging the reasons and role in the failure was a necessary step in overcoming the failure and is in line with the results of a grounded theory study done by Karsten and DiCicco-Bloom. ${ }^{[15]}$ The ten participants for this study each had their unique way of coping and it is important to note that their way of coping and its outcome was again tied to the realizations or new meaning they have attached to that experience. That is the reason why in figure three this theme is again connected to the core category of Finding 
New Meanings, which drove each participant not to give up but build new and more effecting ways to cope with the experience of attrition.

\subsubsection{Changes and modifications}

The axial codes under this theme discussed earlier demonstrate the vital changes that the participants had to institute in the interrelated aspects of their personal, work, family and school life in order to overcome the period of attrition and progress into the program. A major suggestion by all the participants was to utilize all the resources available to them, not only within the school but also in the external environment of their families, peers and workplace if available. This finding is in line with the results of a grounded theory study done by Karsten and DiCicco-Bloom ${ }^{[15]}$ on the importance of seeking help during the nursing program. For the ten participants, the help took many forms, from academic to financial, emotional and even physical support such as assistance with childcare and household chores. These different forms of support enabled them to succeed in the program. This theme was evident in all phases of attrition as each participant explored the challenge of try to modify pre-existing life-situations or habits that were previously effective in dealing with life crisis but is now ineffective that lead to their attrition experience.

\subsubsection{Finding new meanings}

This core category was evident as each participant gained awareness of the perceived factors that lead to their attrition, as well as the realization of the things they had to change in order to adapt and succeed into the program. This core category transcended even after the period of attrition when each participant on hindsight had a better meaning for their experience beyond the superficial academic failure that caused it.The realizations and meanings that each participant arrived at in this phase of the experience was overall in a positive light. All of the participants in hindsight realized that their current state in life is a result of the complex attrition to completion experience. Granted the journey through nursing school took longer than expected, but all ten participants attached a positive value to it, which was a complete opposite of their perceptions when they were in the attrition phase of the process. This finding is in line with Gerow's ${ }^{[16]}$ phenomenological inquiry in the life of nursing students who experienced failure and success in which the theme of transforming and integrating the experience had been in some ways valuable from the perspective of having completed school and are already practicing nurses. The core category of the emerged theory of this study Finding New Meanings can be clustered under Carper's ${ }^{[17]}$ pattern of personal knowing. The pattern of personal knowing refers to the quality and authenticity of the interpersonal process between each nurse and each patient. ${ }^{[18]}$ In the case of the emerged theory, this refers to the interpersonal processes between the study participants to all the other people they came in contact with during their journey in the nursing program. Personal knowing in the context of the emerged theory is not just about internal reflection about one's self, but rather knowing how to adjust one's ways and priorities based on the ever changing situations in one's life. Personal knowing is developed by means of opening and centering the self to thinking about how one is or can be authentic, by listening to responses from others, and by reflecting on those thoughts and responses. ${ }^{[18]}$ In the context of the emerged Attrition to Completion Progression Theory, the pattern of personal knowing is continuously finding new meanings and authentically allowing these realizations to guide better decision making for improved outcomes during periods of crisis such as the process of attrition explored in this study.

\subsection{What additional student resources and support sys- tems that would assist in decreasing student attrition rate in the Associate Degree in Nursing program?}

\subsubsection{Current and future nursing students}

An overreaching theme that was expressed by all the participants is to utilize the resources already available in the program. Another suggestion was training the new and current students on how to improve their time management skills. This involves teaching the students ways on how they balance their time for studying and the other demands of their other life roles.

\subsubsection{Nursing faculty and staff}

The faculty could be more consistent in the conceptual-based learning curriculum. Another suggestion is developing ways to enhance time management skills, as well as the ability to prioritize clinical decisions in each of the courses throughout the curriculum. Particularly in the clinical setting, where effective and efficient time management is an essential tool, each nurse must develop these skills as a component of quality patient care. Another suggestion was to organize the faculty tutoring based on the faculty member's strengths, experience and area of specialty. Another suggestion was to have students who actually experienced attrition within the program share their experiences and how they overcame it during new student orientation. Another suggestion was to have tutoring opportunities already built in the program and not have to ask for it or set it up. Another suggestion was to bring back the nursing students' appreciation day when the faculty organized a get together among the different year levels. This provided an opportunity for students to mingle, as well as for the lower classmen to get tips and suggestions from the upper classman on how to be successful in 
the program. Final suggestion was to work on improving the communication between the participants of the Nursing Ambassador program as the semester progresses.

\subsubsection{Institutional administrators}

A suggestion that is probably geared towards the administration level is for the program or campus to provide resources to promote and maintain positive mental health considering how stressful the nursing program is as a whole. Overall, the participants just wanted the faculty and staff to continue on what they were doing. This was evident in several statements shared by the participants.

\subsection{What are the implications of the developed theory to the institution?}

\subsubsection{Pre-Attrition phase}

1) Ask volunteer students who experienced attrition during the program to share relevant experience about attrition to new students during freshmen orientation.

2) Identify students with diagnosed or known learning disabilities in the first semester and offer tutoring and other appropriate resources early in the semester.

3) Continue to post on on-line sites and visibly by faculty offices faculty's schedule of available hours for outside of class meeting for students to clarify questions.

4) Review first semester courses for curriculum content to include and strengthen strategies for success (e.g. identifying what type of learner, study techniques, time management).

5) Identify at risk students below $80 \%$ grade standing per course by program director led mid-semester evaluations.

6) Assign faculty tutor to at risk student, taking into consideration the student's area of need and the faculty member's specialty and teaching load.

7) Utilize Campus tutors for general education tutoring needs (e.g. Math, study techniques, testing techniques).

8) Assign volunteer students within similar age group who experienced attrition during the program to mentor identified at risk students after mid-semester evaluation. This is to address the factor of age expressed by the participants, which would allow at risk students to find realistic similar solutions from successful returning students who are similar in age.

9) Strengthen the Ambassador Program by creating more delineated roles and responsibilities between the ambassador and mentee to achieve continuity of mutual support throughout each semester.

10) Work with individual returning student to create a plan for success that they can follow and complete while in attrition to create specific, measurable, attainable, realistic and time-bound goals on how to address the identified cause of the attrition for the failed course.

11) Develop a series of workshops that can be offered to

Published by Sciedu Press freshmen students on the different aspects of effective study habits that will help them acquire skills related but not limited to various methods to develop critical thinking and efficient time management.

12) Update and renew the Calendar for Success each student was required to submit during their application into the program. The calendar will be reviewed and signed by the student and their family members each semester to address the factor of family-role conflict shared by the participants as a factor leading to attrition. This will facilitate the students to open up to their families on the rigors of the program each semester and the support they need to succeed.

13) The administration together with the Nursing faculty and staff will host a Family Night on the first week of the semester where a new freshman cohort starts. Family members of the new students can come to campus to listen to presentations of upperclassmen students and alumni who experience attrition on the rigors of the nursing program and how important their roles are in helping their family member become successful each semester.

14) Submit a request to the administration to provide on campus, an area for physical release of stress and tension. This is to assist in managing the stress associated with the unexpected rigor of the program shared as one of the factors leading to attrition. Ideas on what the activities to be included in the room can be surveyed from the current students or through a suggestion box that can be open to all students in the campus and not just for the nursing department.

15) Submit a request to administration to look into the feasibility of having a child care center on campus or near an off-campus site where working single parents can leave their children at a more affordable cost while attending their classes. This is to address the concern of family-role conflict expressed by the study participants who were single parents. 16) Continue with semi-annual observation of all faculty by the Program Director and Campus Faculty Coordinator to assure that each faculty is utilizing appropriate instructional style to meet the needs of the curriculum content and unique needs of each student cohort. This is to address the factor shared by the study participants related to difficulty with each faculty's instructional style.

17) Develop faculty in-service training series based on the needs identified by the Program Director and Campus Faculty Coordinator during individual faculty semi-annual classroom observation.

18) Train faculty members on cognitive mapping and other non-linear assessment tools that can be utilized in explaining concepts through exemplars. This is to address one of the factors indicated by the study participants pertaining to the unexpected rigors of the nursing program. Having the faculty 
model learning techniques geared toward critical thinking and judgment in the classroom is one way to teach the students on how to learn and correlate multiple concepts as they progress through the nursing curriculum.

\subsubsection{Attrition Phase}

1) Implement a schedule for Program Director to periodically check on students in attrition, highlighting their coping level. 2) During periodic checks by Program Director during attrition period, offer resources the student may need to prepare for their transition back into the program.

3) Schedule the student services representative follow-up on student status during period of attrition so student feels integrated into the program and campus affairs during their attrition period.

4) Have an alumnus or current student who experienced attrition in the program volunteer to be a resource person and a source of inspiration to build a supportive relationship with the student currently in attrition on how to overcome the attrition experience.

5) Schedule the student to come back at least two weeks before the start of the semester when the returning student will retake the failed course to be introduced to a volunteer ambassador who belong with the new cohort the returning student will be joining. This is to facilitate establishing rapport prior to the official start of their transition back into the program.

\subsubsection{Transition phase}

1) Institute a concrete weekly follow-up program with returning student to an assigned faculty mentor in order to monitor and provide continued support for student as they transition to a new cohort beginning from week 1 of the semester, they return to prevent regression.

2) Implement a weekly check in between the student and student services to actively aid the student in adjusting to the new cohort, and to provide additional resources they may need to be successful.

3) Continue meeting with volunteer student ambassador coming from the new cohort to help the returning student integrate better and faster into the group.

4) Offer, if applicable for student to audit other courses in the semester to help in reviewing other courses they are not taking at the moment.

5) Include a mandatory check-off of the skills expected in the semester the returning student is in, if the repeat course they have to take does not have the skills laboratory part of the course. This is to help the student stay up to date with the skill set expected at their level to maximize learning and minimize feelings of inadequacy.

\subsubsection{Post-attrition phase}

1) Institute weekly follow-ups with faculty mentor to prevent regression into ineffective study habits or specific attrition reason the returning student experienced in the past. The frequency can be decreased once student has substantially demonstrated stable adjustment to coming back to a full semesters' load after passing the failed course from the transition phase.

2) Implement a weekly check in between the student and student services to prevent regression by provide additional resources they may need to be successful. The frequency can be decreased once student has substantially demonstrated stable adjustment to coming back to a full semesters' load after passing the failed course from the transition phase.

\section{Conclusions}

The emergent Attrition to Completion Progression Theory resulting from this study described the complexity of the multiple perceived factors of attrition that the study participants shared. The emerged Attrition to Completion progression Theory is composed of three main themes and one core category. The themes that emerged are: Attrition is an interplay of multiple factors; Ways of coping with attrition; Changes and modifications; and Finding new meanings as the core category.

The emergent theory and thick descriptions of the participants' experiences resulted in specific suggestions on areas the current students, faculty, staff and administration of the institution can continue to do that the participants perceived as positive factors that helped them overcome their attrition. Conversely, the participants also shared suggestions on areas can be changed or improved to prevent future nursing student attritions and assists returning students to transition back into the program with more ease and successfully complete the program. The emergent theory also assisted in identifying concrete actions plans that the faculty, staff and administration reflected on after peer review and focus group discussion on the recommendations shared by the study participants.

The findings of this study support the need for continued and periodic assessment of the unique circumstances surrounding each student's risk-factor for attrition from the pre-attrition phase all the way to the post-attrition phase to prevent repeat incidences of regression into another attrition episode.

\section{Recommendations}

Current and future nursing students can utilize available student resources such as campus tutors, individual faculty tutors and student ambassadors early on in every semester. Findings of the study imply that nursing students should update and adhere to the Student's Calendar for Success orig- 
inally submitted during the interview when applying into the nursing program and share this calendar with family and other external support systems available to each individual student to clearly communicate their needs related the change in their family roles while in the nursing program. This will assist in setting realistic goals of the time needed to be allocated to studying to be successful in the program.

The findings suggest that administrators and educators can utilize the open-door policy of faculty and administrators of the program to pro-actively discuss unique individual developmental or situational crisis that might arise while in the program. This will assist in finding collaborative solutions prior to an actual attrition from occurring. Faculty can periodically assess and identify students at risk for attrition early on in the semester by keeping an open-door policy for student counseling outside of class hours. This can be done by setting mandatory meeting with students who fail to meet the minimum passing grade for every test. This will allow the faculty and student to go over the concepts missed in the test or skills check-off and create an individualized plan of action with the student with consistent follow-up to prevent further academic deterioration. Faculty can also identify cliques existing in each cohort and provide in-class activities or group assignments that will break up these groups and open each student to building new and varied relationships with other classmates. This will also provide for returning students to integrate into the new cohort and not feel isolated because of the perceived cliques when groups are not regulated. This will also provide opportunities for team building and exposing students for the opportunity to cope with change in the professional setting. Results also imply for faculty to attend continuing education activities related to identifying the different learning styles of each student and how to adjust the faculty's instructional style that best fits the curriculum content of the course being taught and the unique needs of each cohort of students. Faculty can also utilize a variety of non-linear teaching styles and techniques that can stimulate the interest and focus of non-traditional students to develop the necessary critical thinking skills essential to the practice of nursing.

Faculty and administrators can continue scheduled and periodical curriculum assessment based on the identified strengths and weaknesses of each cohort going through the program in accordance with the standards set by recommending bodies related to current evidence-based practices and in accordance to the Nurse Practice Act. Administrators may also investigate the feasibility of having a dedicated area in campus or near an off-campus site for students to have an affordable child care center while they are attending classes. As well as investigate the feasibility of having a dedicated area in campus where students can have some quiet time or recreational opportunities in between classes to manage the stress resulting from the rigors of the nursing program and available for other students in the campus as well. Administrators may also form a committee composed of alumni, current students, faculty and administrators to review current workflows and policies related to attrition and incorporate the results of this current study to decrease student attrition, improve student transition back into the program and increase program completion rates.

Study results also imply for future researchers to conduct a longitudinal evaluative study to assess the attrition and retention rate of the program after the above recommended changes are instituted. As well as replicate the study to other Associate Degree Nursing programs both public and private schools in the state and other states to assess the transferability of the emerged theory.

\section{CONFlicts OF InTEREST Disclosure}

The authors declares that there is no conflict of interest.

\section{REFERENCES}

[1] Snavely TM. A Brief Economic Analysis of the Looming Nursing Shortage In the United States. Nursing Economics. 2016; 34(2): 98-100.

[2] Stickney MC. Factors Affecting Practical Nursing Student Attrition. J. Nurs. Educ. 2008; 47(9): 422-5. PMid:18792710 https: //doi.org/10.3928/01484834-20080901-07

[3] Newton SE, Moore G. Use of aptitude to understand bachelor of science in nursing student attrition and readiness for the National Council Licensure Examination-Registered Nurse. Journal of Professional Nursing: Official Journal of the American Association of Colleges of Nursing. 2009; 25(5): 273-278. PMid:19751931 https://doi.org/10.1016/j.profnurs.2009.01.016

Published by Sciedu Press
[4] Urwin S, et al. Understanding student nurse attrition: learning from the literature. Nurse Educ. Today. 2010; 30(2): 202-207. PMid:19910083 https://doi.org/10.1016/j.nedt.2009.07 .014

[5] Anonymous. Nursing and Healthcare Research at a Glance Glasper Alan Rees Colin Nursing and Healthcare Research at a Glance 224pp $£ 26.99$ Wiley Blackwell 97811187787911118778790 [Formula: see text]. Emergency Nurse: The Journal of the RCN Accident and Emergency Nursing Association. 2017; 25(2): 15. PMid:28494672 https://doi.org/10.7748/en.25.2.15.s17

[6] Anonymous. Constructing Grounded Theory: A practical guide through qualitative analysis Kathy Charmaz Constructing Grounded Theory: A practical guide through qualitative analysis Sage 224 
$£ 19.9907619735320761973532$ [Formula: see text]. Nurse Researcher. 2006; 13(4): 84. PMid:27702218 https ://doi.org/10 $.7748 / \mathrm{nr} .13 .4 .84 . \mathrm{s} 4$

[7] El Hussein T, Kennedy A, Oliver B. Grounded Theory and the Conundrum of Literature Review: Framework for Novice Researchers. The Qualitative Report. 2017; 22(4): 1199-1210.

[8] Anonymous. Research for nurses; methods and interpretation. Scitech Book News. 2001. Available from: https://search.proquest . com/docview/200088096?accountid=89121

[9] Banta BM. Recording oral history: a guide for the humanities and social sciences. Choice. 2015; 52(11): 1901. https://doi.org/ 10.5860/CHOICE. 190801

[10] Cameron J, et al. An integrative literature review of student retention in programmes of nursing and midwifery education: why do students stay? J. Clin. Nurs. 2011; 20(9-10): 1372. PMid:21269343 https://doi.org/10.1111/j.1365-2702.2010.03336.x

[11] Deleon C. Navigating the storm: Integrative review of attrition factors among undergraduate nursing students. Health Notions. 2016; 2(9): 918-926.

[12] Lisa SL. The stories of nursing student repeaters: A narrative inquiry study. Nurse Education in Practice. 2018; 2: 109-114.
PMid:29073512 https://doi.org/10.1016/j.nepr. 2017.10 .015

[13] Tabi M, Thornton K, Garno M, et al. Minority nursing students' perception of their baccalaureate program. Journal of Nursing Education and Practice. 3(9): 167-175.

[14] Yucha CB, Kowalski S, Cross C. Student stress and academic performance: home hospital program. J. Nurs. Educ. 2009; 48(11): 631-637. PMid:19731889 https ://doi.org/10.3928/01484834-20090 828-05

[15] Karsten K. Reconciling Life Balance: A Grounded Theory Study of Overcoming Failure. Order No. 3589732, City University of New York, Ann Arbor, 2013.

[16] Gerow LH. The Experience of Nursing Student Failure and Success: A Phenomenological Inquiry. Order No. 3490763, University of Kansas, Ann Arbor, 2011.

[17] Carper B. Fundamental patterns of knowing in nursing. ANS. Advances in Nursing Science. 1978; 1(1): 13-23. PMid:110216 https : //doi .org/10.1097/00012272-197810000-00004

[18] Fawwcett L, et al. On nursing theories and evidence. Journal of Nursing Scholarship. 2001; 33(2): 115-9. PMid:11419305 https : //doi.org/10.1111/j.1547-5069.2001.00115.x 